Article

\title{
Successful Establishment of Hepatitis E Virus Infection in Pregnant BALB/c Mice
}

\author{
Chenchen Yang ${ }^{1,+}$, Xianhui Hao ${ }^{1,+}$, Yunlong Li ${ }^{1}$, Feiyan Long ${ }^{1}$, Qiuxia He ${ }^{1}$, Fen Huang ${ }^{1, *(D)}$ \\ and Wenhai $\mathrm{Yu}^{2, *}$ \\ 1 Medical School, Kunming University of Science and Technology, Kunming 650500, China; \\ yangchenchen0329@163.com (C.Y.); haoxianhui226@163.com (X.H.); liyunlong9018@163.com (Y.L.); \\ longfeiyan24@163.com (F.L.); heqiuxia19941105@163.com (Q.H.) \\ 2 Institute of Medical Biology, Chinese Academy of Medical Sciences and Peking Union Medical College, \\ Kunming 650118, China \\ * Correspondence: huangfen6789@163.com (F.H.); wenhaiyu1234@163.com (W.Y.) \\ + These authors contributed equally to this work.
}

Received: 25 March 2019; Accepted: 14 May 2019; Published: 17 May 2019

check for updates

\begin{abstract}
Worldwide, the Hepatitis E virus (HEV) is the main pathogen of acute viral hepatitis, with an extremely high mortality in pregnant women. However, the pathogenesis of HEV infection in pregnant women remains largely unknown. We established an HEV-infected pregnant mice animal model to explore the adverse pregnancy outcomes of HEV infection. Mice were infected with HEV in their early, middle and late stages of pregnancy. HEV RNA was detected in the tissues (liver, spleen, kidney, colon, uterus and placenta) of pregnant mice. HEV antigens were also detected in these tissues of HEV-infected pregnant mice. Miscarriages (7/8, 87.5\%) occurred in pregnant mice infected with HEV in the middle of pregnancy. Th1-biased immune status was found in these aborted mice. Vertical transmission was confirmed by HEV replication in the uterus and placenta, as well as in the positive HEV RNA and HEV antigen positive in fetal livers. The successful establishment of HEV infection in pregnant mice is beneficial for further study of HEV pathogenesis, especially the adverse pregnancy outcomes caused by HEV infection.
\end{abstract}

Keywords: hepatitis E virus; pregnancy; miscarriage; vertical transmission

\section{Instruction}

Hepatitis E virus (HEV) is an emerging infectious agent that causes acute viral hepatitis worldwide. Each year, more than 20 million estimated cases of HEV infection occur globally, resulting in 70,000 deaths [1]. HEV has at least eight genotypes [2,3]. Genotypes 1 and 2 are known to circulate in developing countries for more than half a century and only infect humans [1]. HEV genotypes 3, 4, and 7 can zoonotically transmit between animals and humans and are the ones that are considered emergent [2]. Hepatitis $E$ is usually self-limited, with a case-fatality rate of $<1 \%$ among the general population [3], but a significantly high mortality $(20 \% \sim 30 \%)$ in the third trimester of pregnant women [4-6]. Genotype $1 \mathrm{HEV}$ infection during pregnancy has been reported to result in severe placental diseases, such as hemorrhage, miscarriage, and stillbirth [7-9]. Genotype 4 HEV infections in pregnant women have usually been ignored. Recently, 33.33\% (8/24) of anti-HEV IgM positive pregnant women in China where the prevalent genotype $4 \mathrm{HEV}$ has adverse pregnancy outcomes, including four threatened preterm births, three premature ruptures of membranes and one threatened abortion [10]. More severe pregnancy outcomes were reported in both anti-HEV IgM and IgG positive pregnant women with a $72.22 \%(13 / 18)$ occurrence of poor pregnancy outcomes, including 10 threatened preterm births, two premature ruptures of membranes and one threatened abortion [11]. Genotype 4 HEV 
infection in pregnant women in China resulted in stillbirth, preterm premature rupture of membranes, and fetal distress; and pregnancy induced hypertension syndrome has also been reported [11,12]. However, the pathogenesis of HEV infection in pregnant women remains unknown.

The interplay of hormonal and immunologic changes during pregnancy, along with the high viral load of HEV, may be the reason for woman being more vulnerable to HEV [13,14]. HEV replication in placental-derived cells (JEG-3) [15] and in a maternal-fetal interface using the decidua basalis and fetal placenta [7] in vitro made great contributions to the study of HEV pathogenic mechanisms. However, an animal model is necessary to investigate the underlying severity of hepatitis $E$ in pregnancy and to better understand its pathogenesis. HEV-infected pregnant rabbit animal models have been successfully established, resulting in a 75\% mortality rate and a $33.3 \%$ miscarriage rate [16]. Vertical transmission was confirmed by the presence of HEV RNA and antigen in the placenta of HEV-infected rabbits [16]. Although rabbit HEV can infect non-human primates [17] and the recently isolated HEV from humans shares a close relationship with rabbit HEV [18], the rabbit HEV shares less than an $82 \%$ similarity to human HEV or swine HEV [19]. Therefore, an alternative or common animal model, for example, one using BALB/c mice, which are sensitive to HEV infection [20,21], should be established to further study the mechanism of HEV infection in pregnancy.

In the present study, pregnant BALB/c mice were successfully infected with genotype 4 swine HEV. HEV RNA was detected in the feces, serum, and tissues by RT-nested PCR (RT-nPCR) and quantitative RT-PCR (qRT-PCR). Meanwhile, HEV antigens were analyzed in the liver, spleen, kidney, and colon by immunohistochemistry. Moreover, vertical transmission was confirmed by the presence of HEV RNA and HEV antigens in the uterus, placenta, and fetal livers of the newborn mice.

\section{Materials and Methods}

\subsection{Ethics Statement}

All animal experiments were approved by the Animal Care and Use Committee of Kunming University of Science and Technology. We followed the guidelines of the Kunming University of Science and Technology Animal Care and Use Committee when handling the experimental animals during this study. Thirty-six female BALB/c mice, 6 week old, weighing 18 22 g, were obtained from SLAC Animal Laboratory (China). Their food and water were sterilized, and the experimental animal rooms were fumigated. Prior to inoculation with HEV, the mice were confirmed negative for HEV antibodies by enzyme-linked immunosorbent assay (ELISA), and no HEV RNA was detected in the serum and feces of all experimental animals.

\subsection{Virus}

Swine fecal samples containing HEV genotype 4 (KM01, GenBank No. KJ155502) were obtained from a village in Southwestern China. The fecal suspension $(10 \%)$ was centrifuged at $12,000 \times g$ at $4{ }^{\circ} \mathrm{C}$ for $10 \mathrm{~min}$, filtered through 0.45 and $0.22 \mu \mathrm{m}$ microfilters, and treated with penicillin and streptomycin at $4{ }^{\circ} \mathrm{C}$ for $1 \mathrm{~h}$. The HEV titer in suspension was $1.0 \times 10^{4}$ copies $/ \mathrm{mL}$, and the fecal suspension was stored in liquid nitrogen until use.

\subsection{Experimental Design}

All female mice $(n=36)$, as candidates for pregnancy, were randomly divided into four groups as illustrated in Figure 1. Normal copulated group (MOCK, $n=9)$, mice were injected with PBS after copulation; the early pregnancy of the HEV infection group $(n=9)$ occurred when individual female mice were copulated with individual adult male mice for 3 days. Then the mice were intravenously (i.v.) injected with HEV $(200 \mu \mathrm{L})$; during the middle pregnancy of the HEV infection group $(n=9)$, individual female mice were pre-copulated with individual adult male mice, then HEV was intravenously (i.v.) inoculated $(200 \mu \mathrm{L})$ after 10.5 days of copulation; during the late pregnancy of the HEV infection group $(n=9)$, individual female mice were pre-copulated with individual adult male mice. Then 
HEV was intravenously (i.v.) inoculated $(200 \mu \mathrm{L})$ after 14 days of copulation. The insemination process occurred as follows: One female mouse copulated with one healthy adult male mouse (8 to 10 weeks old) in individual cage, then the couple was separated when the vaginal plug was observed $1 \sim 3$ days after being caged together. To determine whether the mouse was pregnant, estrogen and progesterone concentration were tested. At 7, 14 and 19/20/21 days post-copulation, the serum estrogen and progesterone levels were detected. If the level of estrogen and/or progesterone kept elevating, the mice were defined as pregnant; if the level elevated first and then declined, the pregnancy was defined as a miscarriage; if it remained unchanged, the mice were defined as non-pregnant.

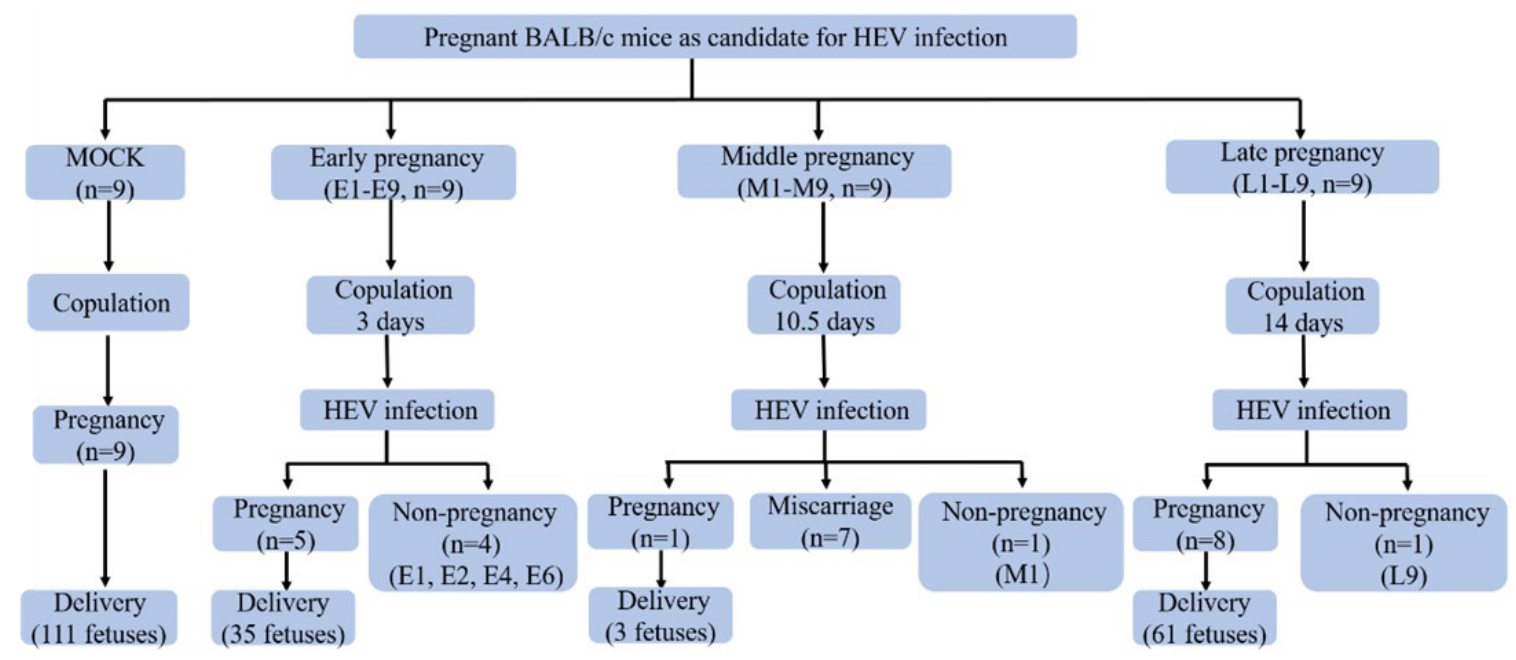

Figure 1. Effects of Hepatitis E virus (HEV) infection in the pregnant BALB/c mice.

Non-pregnant mice in the early pregnancy group $(n=4)$ at 7 dpi were treated with ribavirin (RBV, 50mg/kg/day) for 10 days to evaluate the specificity of the HEV titer. All mice were humanely euthanized and necropsied after delivery, and had a cesarean section or treatment at 19-21 days post-copulation. Stool and blood were collected for HEV RNA detection. Tissues, including liver, spleen, kidney, colon, uterus, placenta, and fetus liver (if available) were collected and stored at $-80^{\circ} \mathrm{C}$ for HEV RNA and antigen detection or fixed in a 10\% neutral buffered formalin for histopathological and/or immunohistochemistry analysis.

\subsection{Determination of Pregnancy-Related Hormones}

To confirm the pregnancy, serum estrogen and progesterone in female mice were determined by EIA Kit following the manufacturer's instructions (Cayman Chemical, Ann Arbor, Michigan CA, USA).

\subsection{HEV RNA Detection and Quantification}

Total RNA was extracted from all samples by Trizol (Invitrogen, Carlsbadd, Califormia America), according to the instructions of the manufacturer. Reverse transcription was performed using M-MLV Reverse Transcriptase (Takara, Kusatsu, Japan) according to the directions of the manufacturer. A 348 nt amplicon from HEV ORF2 was amplified by RT-nPCR as described previously [22]. Negative strand RNA of HEV was detected to further confirm replication according previous study [23]. HEV titer was quantified by SYBR green-based qRT-PCR with HEV-specific primers as previous studies [24,25].

\subsection{Detection of Cytokine Levels}

The levels of Th1 cytokine (interleukin 12, IL-12) and Th2 cytokine (interleukin 6, IL-6) in serum samples were assayed using commercial enzyme-linked immunosorbent assay (ELISA) kits (4A Biotech Beijing, China) according to the manufacturer's instructions. 


\subsection{Immunohistochemistry}

For immunohistochemistry (IHC), the tissues were deparaffinized, hydrated, water bath-heated for antigen retrieval, and then blocked with the addition of $3 \%$ hydrogen peroxide for $10 \mathrm{~min}$. Tissue sections were incubated overnight at $4{ }^{\circ} \mathrm{C}$ with HEV ORF2 specific antibodies (Millipore, Temecula, CA, USA, MAB8003, 1:250 dilutions), washed with PBS for three times, and then incubated with an HRP-labeled goat anti-Mouse IgG antibody at $37^{\circ} \mathrm{C}$ for $60 \mathrm{~min}$. After being washed three times, a DAB substrate (Abcam, Cambridge Science Park, England) was added and Gill's hematoxylin was applied as a background stain. The slides were sealed with neutral balsam, inspected, and photographed under a microscope.

\subsection{Histopathology}

Tissues for histologic examination were fixed in a $10 \%$ neutral buffered formalin, routinely processed, sectioned at a thickness of $3 \mu \mathrm{m}$, and then stained with hematoxylin and eosin (H \& E). The samples were photographed and analyzed under a microscope (Nikon, Tokyo, Japan) equipped with a digital camera.

\subsection{Statistical Analysis}

All experiments were performed at least thrice. GraphPad Prism 5.01 software was used for statistical analysis. A student- $t$ test analysis was used to determine the significance of differences between two groups. $p$ value $<0.05$ was considered statistically significant.

\section{Results}

\subsection{HEV Successfully Infected Pregnant BALB/c Mice}

Hepatitis E infection causes a high mortality (about 20\%) in pregnant women, with an increasingly high incidence and severity in the third trimester of pregnancy [26]. However, the mechanisms for this high morbidity and mortality during pregnancy remains unclear, because of the unavailable animal models. In this study, pregnant mice in different trimesters of pregnancy were inoculated with HEV. To simulate HEV-infection in pregnant women in different trimesters of pregnancy, mice were inoculated with HEV at 3 days (early pregnancy), 10.5 days (middle pregnancy), and 14 days (late pregnancy) post-copulation. Four mice in the early pregnancy group were not pregnant, and one mouse in the middle group and one mouse in the late pregnancy were not pregnant, as defined by unchanged estrogen and/or progesterone (Figure 1, Figure 2A,B). Interestingly, HEV RNA was detected in the feces at 3 5 dpi and in the serum at 5 7 dpi (Figure 2C-E, Table 1). Viremia was observed in all infected pregnant mice (Figure 2). The viral titer in the serum of the HEV-infected miscarriage mice was compared with that of the non-pregnant mice and delivery mice at $7 \mathrm{dpi}$ in the early and middle groups (Figure 2F). A negative strand of HEV RNA was also detected in the serum (Table 1). The relative expression of negative-strand HEV RNA in the serum was compared among non-pregnant, normal delivery and miscarriage mice at $7 \mathrm{dpi}$ in the early and middle pregnancy groups (Figure $2 \mathrm{G}$ ). To evaluate the specificity of HEV, RBV was applied to treat HEV-infected non-pregnant mice in the early pregnancy group. Fortunately, mild antiviral effects were obtained in the liver and uterus of mice treated with RBV compared with the untreated mice (Figure $2 \mathrm{H}$ ). In addition, positive and negative strands of HEV RNA were also detected in the liver, spleen, kidney, and colon of HEV-infected pregnant mice (Figure 2I-K, Table 1). All pregnant mice infected with HEV in the early pregnancy $(5 / 5)$ or the late pregnancy $(8 / 8)$ has a normal delivery, while only one mouse infected with HEV in the middle pregnancy had a normal delivery $(1 / 8)$. Miscarriages $(7 / 8,87.5 \%)$ happened in the mice infected with HEV in the middle of pregnancy (Figures 1 and 2). The feces, serum, and tissues of mock mice inoculated with PBS were all negative to HEV RNA. 

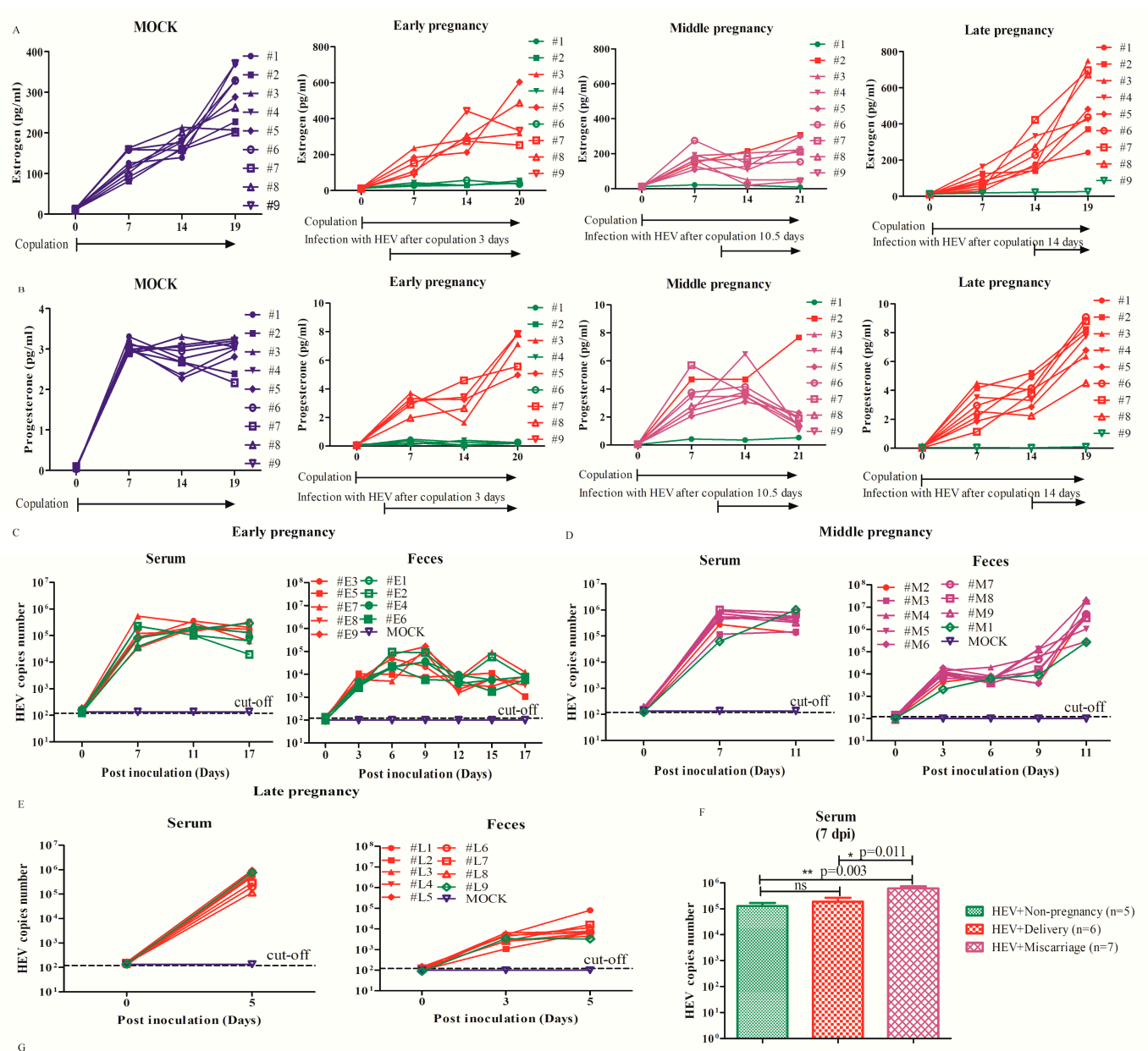

HEV+Non-pregnancy $(\mathrm{n}=5)$ ⿶ HEV+Miscarriage (n=7)

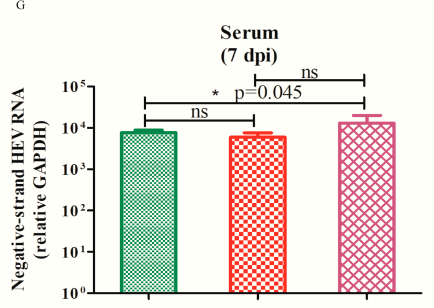

HEV+Non-pregnancy $(\mathrm{n}=5)$

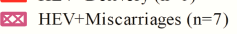
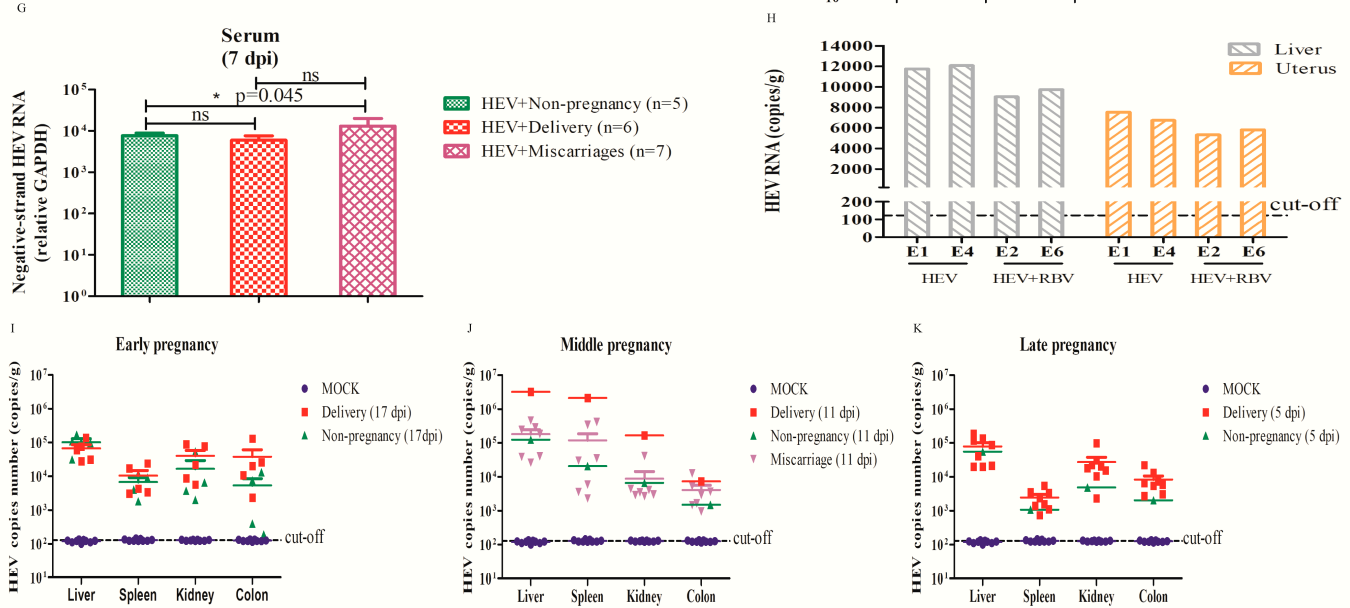

Figure 2. Profile of HEV infection in pregnant mice. The concentration of estrogen (A) and progesterone (B) in mice infected with or without HEV in the early, middle and late stages of pregnancy. The viral titer of HEV in the feces and serum of mice in early (C), middle (D) and late (E) pregnancy. (F) Comparison of the viral titer in serum among non-pregnant $(n=5)$, delivery $(n=6)$ and miscarriage $(n=7)$ mice in early and middle pregnancy at $7 \mathrm{dpi}$. (G) The relative expression of negative-strand HEV RNA in the serum of HEV-infected non-pregnant $(n=5)$, delivery $(n=6)$ and miscarriage $(n=7)$ mice in early and middle pregnancy at 7 dpi. (H) The viral titer of HEV in liver and uterus in HEV-infected non-pregnant mice in early pregnancy treated with or without or RBV. (I-K) The viral titer of HEV in the tissues of mice in early $(\mathbf{I})$, middle $(\mathbf{J})$ and late $(\mathbf{K})$ pregnancy. Mock mice are drawn in a blue colour, non-pregnant mice are drawn in a green colour, delivery mice are drawn in a red colour, and miscarriage mice are drawn in a purple colour. 
Table 1. HEV RNA detection in HEV-infected pregnant mice.

\begin{tabular}{|c|c|c|c|c|c|c|c|c|c|c|c|}
\hline \multirow{3}{*}{ Sample } & \multirow{3}{*}{ Strands } & \multicolumn{10}{|c|}{ Groups } \\
\hline & & \multirow{2}{*}{ MOCK } & \multicolumn{3}{|c|}{ Early Pregnancy } & \multicolumn{3}{|c|}{ Middle Pregnancy } & \multicolumn{3}{|c|}{ Late Pregnancy } \\
\hline & & & Del & NP & Mis & Del & $\mathbf{N P}$ & Mis & Del & NP & Mis \\
\hline \multirow{2}{*}{ Feces } & Positive & $0 / 9$ & $5 / 5$ & $4 / 4$ & $0 / 0$ & $1 / 1$ & $1 / 1$ & $7 / 7$ & $8 / 8$ & $1 / 1$ & $0 / 0$ \\
\hline & Negative & $0 / 9$ & $5 / 5$ & $4 / 4$ & $0 / 0$ & $1 / 1$ & $1 / 1$ & $7 / 7$ & $8 / 8$ & $1 / 1$ & $0 / 0$ \\
\hline \multirow{2}{*}{ serum } & Positive & $0 / 9$ & $5 / 5$ & $4 / 4$ & $0 / 0$ & $1 / 1$ & $1 / 1$ & $7 / 7$ & $8 / 8$ & $1 / 1$ & $0 / 0$ \\
\hline & Negative & $0 / 9$ & $5 / 5$ & $4 / 4$ & $0 / 0$ & $1 / 1$ & $1 / 1$ & $7 / 7$ & $8 / 8$ & $1 / 1$ & $0 / 0$ \\
\hline \multirow{2}{*}{ Liver } & Positive & $0 / 9$ & $5 / 5$ & $4 / 4$ & $0 / 0$ & $1 / 1$ & $1 / 1$ & $7 / 7$ & $8 / 8$ & $1 / 1$ & $0 / 0$ \\
\hline & Negative & $0 / 9$ & $5 / 5$ & $4 / 4$ & $0 / 0$ & $1 / 1$ & $1 / 1$ & $7 / 7$ & $8 / 8$ & $1 / 1$ & $0 / 0$ \\
\hline \multirow{2}{*}{ Spleen } & Positive & $0 / 9$ & $5 / 5$ & $4 / 4$ & $0 / 0$ & $1 / 1$ & $1 / 1$ & $7 / 7$ & $8 / 8$ & $1 / 1$ & $0 / 0$ \\
\hline & Negative & $0 / 9$ & $5 / 5$ & $4 / 4$ & $0 / 0$ & $1 / 1$ & $1 / 1$ & $7 / 7$ & $8 / 8$ & $1 / 1$ & $0 / 0$ \\
\hline \multirow{2}{*}{ Kidney } & Positive & $0 / 9$ & $5 / 5$ & $4 / 4$ & $0 / 0$ & $1 / 1$ & $1 / 1$ & $7 / 7$ & $8 / 8$ & $1 / 1$ & $0 / 0$ \\
\hline & Negative & $0 / 9$ & $5 / 5$ & $4 / 4$ & $0 / 0$ & $1 / 1$ & $1 / 1$ & $7 / 7$ & $8 / 8$ & $1 / 1$ & $0 / 0$ \\
\hline \multirow{2}{*}{ Colon } & Positive & $0 / 9$ & $5 / 5$ & $4 / 4$ & $0 / 0$ & $1 / 1$ & $1 / 1$ & $7 / 7$ & $8 / 8$ & $1 / 1$ & $0 / 0$ \\
\hline & Negative & $0 / 9$ & $5 / 5$ & $4 / 4$ & $0 / 0$ & $1 / 1$ & $1 / 1$ & $7 / 7$ & $8 / 8$ & $1 / 1$ & $0 / 0$ \\
\hline \multirow{2}{*}{ Uterus } & Positive & $0 / 9$ & $5 / 5$ & $4 / 4$ & $0 / 0$ & $1 / 1$ & $1 / 1$ & $7 / 7$ & $8 / 8$ & $1 / 1$ & $0 / 0$ \\
\hline & Negative & $0 / 9$ & $5 / 5$ & $4 / 4$ & $0 / 0$ & $1 / 1$ & $1 / 1$ & $7 / 7$ & $8 / 8$ & $1 / 1$ & $0 / 0$ \\
\hline \multirow{2}{*}{ Placenta } & Positive & $0 / 111$ & $35 / 35$ & $0 / 0$ & $0 / 0$ & $3 / 3$ & $0 / 0$ & $0 / 0$ & $60 / 61$ & $0 / 0$ & $0 / 0$ \\
\hline & Negative & $0 / 111$ & $35 / 35$ & $0 / 0$ & $0 / 0$ & $3 / 3$ & $0 / 0$ & $0 / 0$ & $60 / 61$ & $0 / 0$ & $0 / 0$ \\
\hline \multirow{2}{*}{ Fetus liver } & Positive & $0 / 111$ & $35 / 35$ & $0 / 0$ & $0 / 0$ & $3 / 3$ & $0 / 0$ & $0 / 0$ & $59 / 61$ & $0 / 0$ & $0 / 0$ \\
\hline & Negative & $0 / 111$ & $35 / 35$ & $0 / 0$ & $0 / 0$ & $3 / 3$ & $0 / 0$ & $0 / 0$ & $59 / 61$ & $0 / 0$ & $0 / 0$ \\
\hline
\end{tabular}

To further identify the replication of HEV in mice, HEV antigens were detected by IHC. Consistent with HEV RNA in tissues of mice, HEV antigens were distributed in the liver, spleen, kidney, and colon of pregnant mice, including normal delivery and aborted mice (Figure 3). However, the uninfected mock mice were negative to the HEV antigen. The results strongly indicate that HEV can replicate in pregnant mice.

\subsection{HEV Infection Leads to Adverse Pregnancy Outcome}

HEV infection usually causes self-limiting diseases but leads to high maternal mortality in pregnant women. The pathogenesis of HEV infection in pregnant women is largely unknown because of the unavailable animal models. Thus, these successfully established pregnant BALB/c mice models were used to assess the adverse effects of HEV infection. Although there is no maternal death, seven mice infected with $\operatorname{HEV}(7 / 8,87.5 \%)$ in the middle pregnancy had a miscarriage (Figures 1 and $4 \mathrm{~A}$ ). Notably, the number of fetuses from HEV-infected mothers was significantly less than that from the uninfected mock mothers (a total of 111 fetuses in the mock group vs the HEV-infected group in early (35 fetuses), middle (3 fetuses), or late (61 fetuses) pregnancy (Figure 4B).

Normal pregnancy is associated with a Th2 biased peripheral cytokine profile [27]. It was reported that Th1 biased immune status is abortion-prone [28]. The fine modulate Th1/Th2 balance is a critical factor in the protection of the fetus against abortions in mice [29]. The Th1 cytokines such as IL-12 and INF- $\gamma$ can cause fetal loss, whereas the Th 2 cytokines, such as IL- 6 and IL-10 are protective [30]. To explore the association between HEV infection and abortion, IL-12 (Th1 cytokine) and IL-6 (Th2 cytokine) were determined by ELISA at 19-21 days post-copulation (Figure 4C,D). Uninfected mice with normal delivery showed a Th2 biased immune status, while a higher IL12/IL6 ratio (9.48 folds) 
was found in the HEV-infected miscarriage mice (Figure 4E). Th1 biased immune status was observed in these aborted mice (Figure 4E). Thus, the disbalance of the Th1/Th2 immune status in HEV-infected mice may contribute to the high rate of miscarriage.
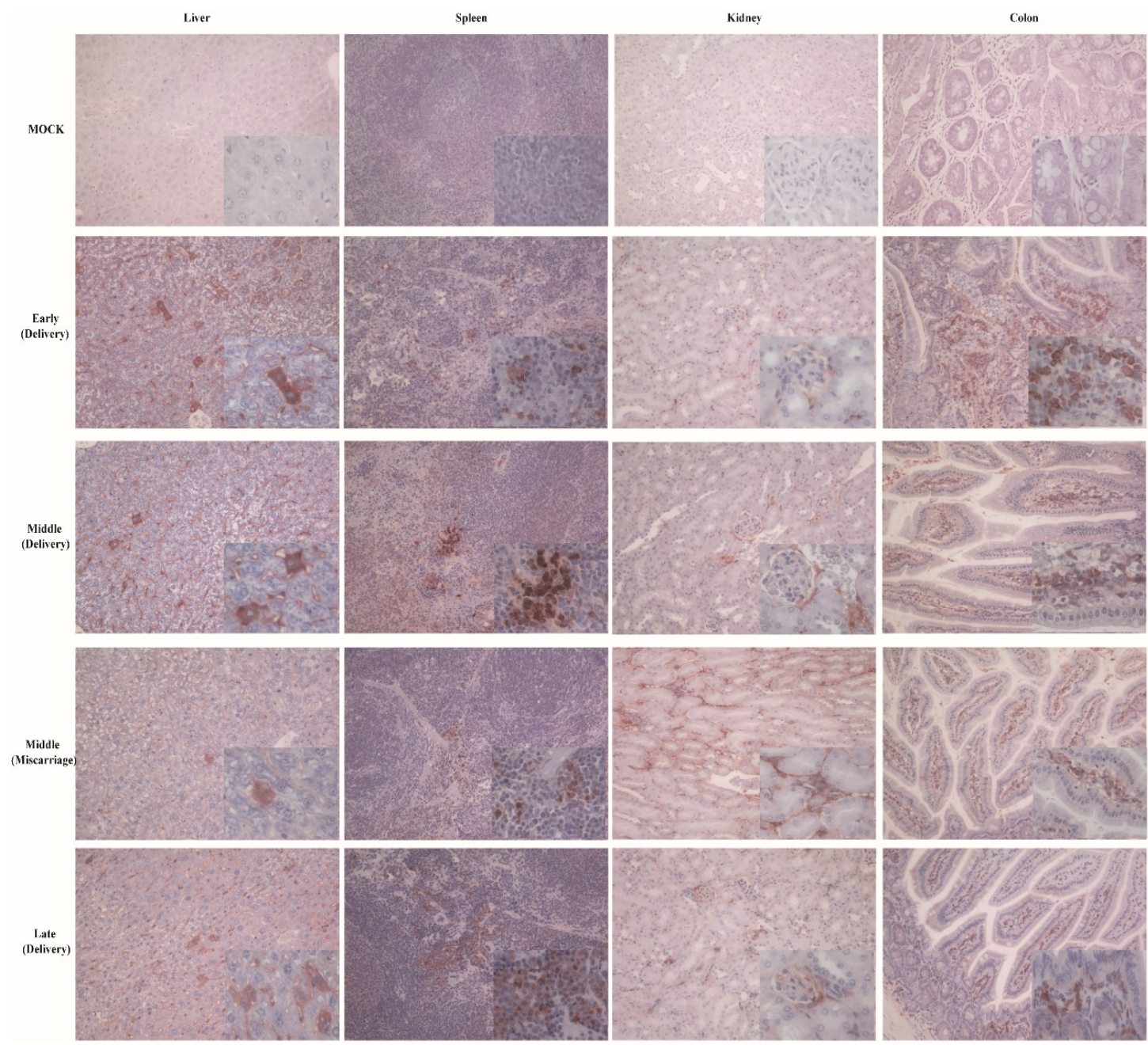

Figure 3. HEV antigens detected by IHC. HEV antigens detected in the liver, spleen, kidney and colon of mice infected with or without $\mathrm{HEV}, \times 20$.

\subsection{HEV Vertically Transmits from Mother to Fetus}

HEV can vertical transmit to the fetus, but the mechanism is remaining elusive. The uterus supplies a safe place for the fetus to develop [31]. The placenta forms the interface between the mother and the fetus, and is able to maintain two separate circulatory systems [32]. The blood-placenta barrier (BPB) is an important barrier to protect the fetus against pathogen infection. However, whether HEV can replicate in the uterus and/or placenta is unclear.

In this study, positive and negative strands of HEV RNA were detected in the uterus and placenta of all the HEV-infected mothers, no matter whether they were infected with HEV during early, middle, or late pregnancy; however, one placenta of a mouse infected in late pregnancy was below the cutoff value (Figure 5A). In addition, HEV antigens were observed in the uterus of all HEV-infected mice, those with both normal deliveries and aborted pregnancies (Figure 5B). Meanwhile, the placenta was also positive to HEV antigens (Figure 5B). Moreover, histopathological changes were analyzed in the uterus and placenta of HEV-infected mice. Severe inflammation responses with inflammatory exudates and hemorrhages were observed in the uterus of aborted mice infected with HEV in middle pregnancy (Figure 5C). Results indicate that HEV replicates in the uterus and placenta. 


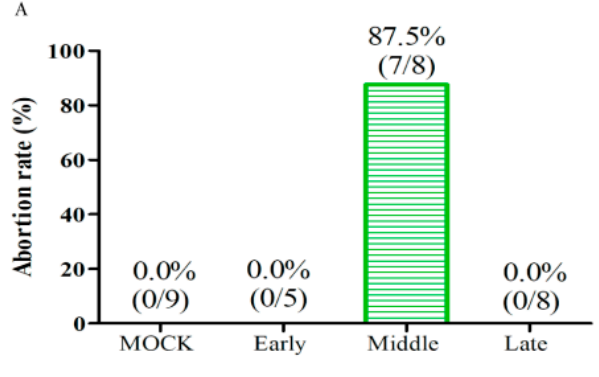

c

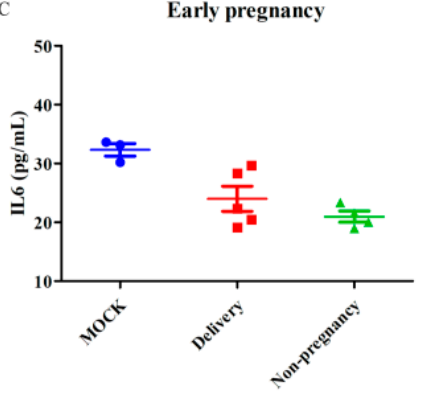

D

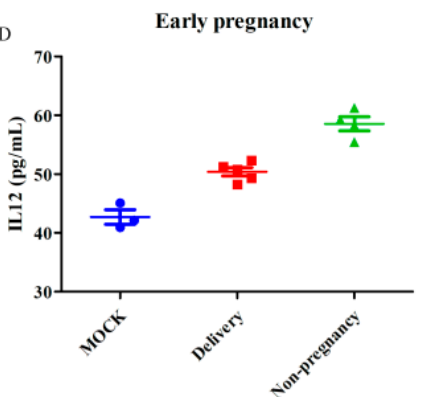

$\mathrm{E}$

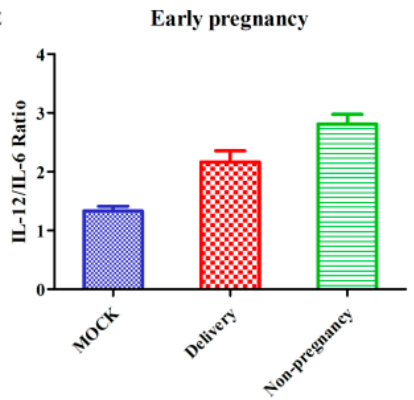

B

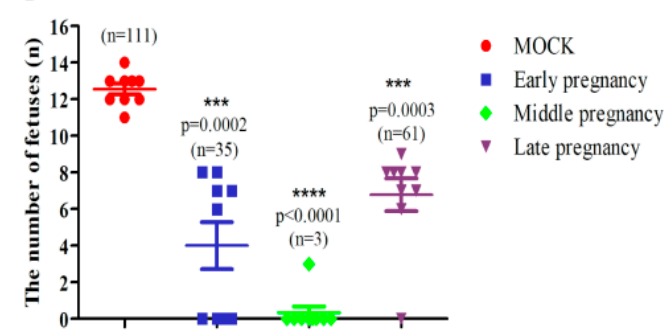

Middle pregnancy
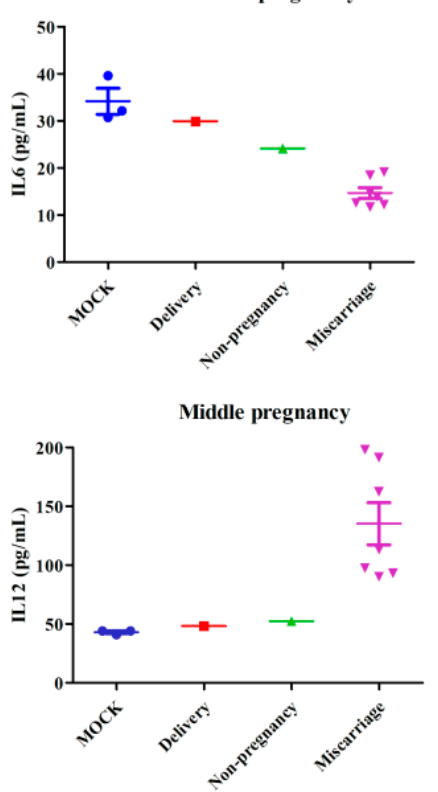

Middle pregnancy

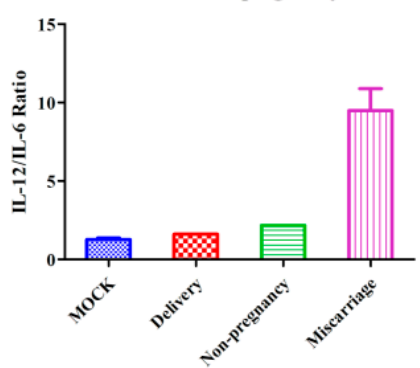

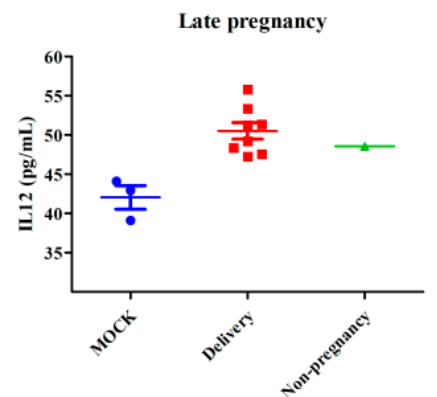

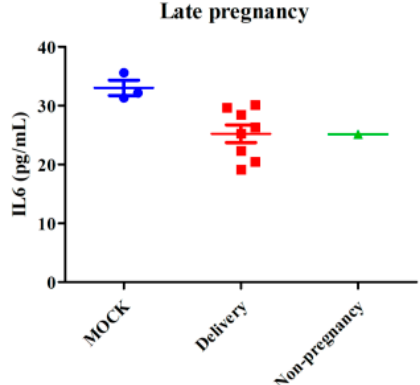

Late pregnancy

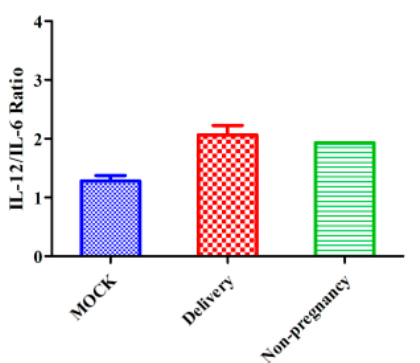

Figure 4. HEV infection leads to adverse pregnancy outcomes. (A) The rate of abortion. (B) The number of fetuses from an uninfected or HEV-infected mother. The concentration of IL-6 (C) and IL-12 (D) in the serum of mice with or without HEV infection. (E) The IL-12/IL-6 ratio in pregnant mice with or without HEV infection.

We investigated whether the fetus suffers from HEV infection, since the uterus and placenta of mother were infected by HEV. Thus, all the livers of fetuses born from HEV-infected mothers who were infected with HEV at the early (fetus $=35$ ), middle (fetus $=3$ ) or late (fetus $=61$ ) stages of pregnancy were used to evaluate HEV infection. Surprisingly, all the livers of fetuses born from HEV-infected mothers were positive for HEV RNA (both positive and negative strands of HEV RNA), except two fetuses that were negative for HEV, whose viral titers were below the cut-off value (Figure 5A). Furthermore, HEV-positive stains were observed in the livers of fetuses born from HEV-infected mothers (Figure 5B). Results strongly suggest that HEV can replicate in the uterus and placenta and vertically transmit to fetuses. 

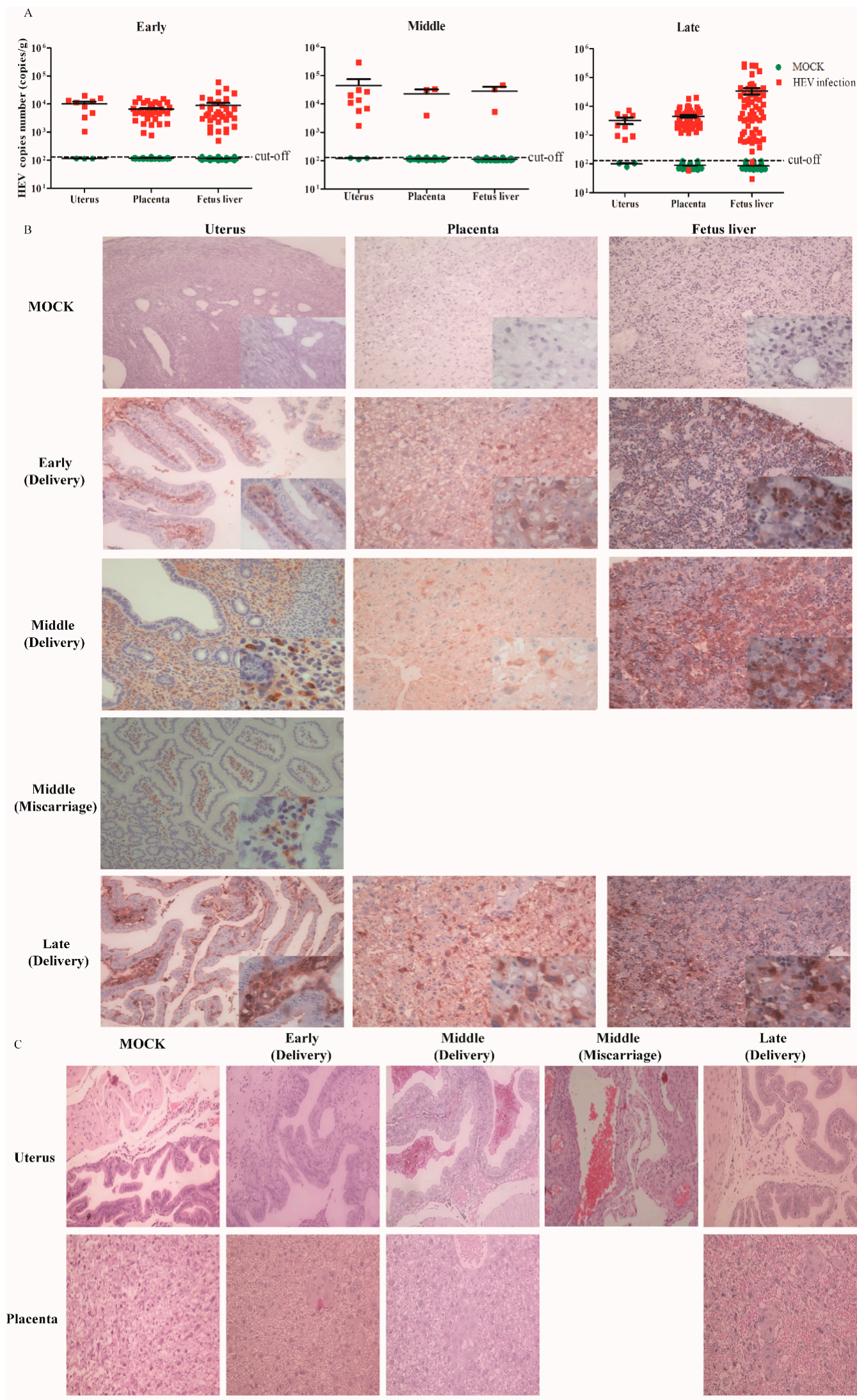

Figure 5. HEV vertically transmits from the mother to the fetus. (A) Viral titer in the uterus and placenta of HEV-infected pregnant mice or liver of fetuses. (B) HEV antigen analysis of the uterus, placenta and liver by IHC, $\times 20$. (C) Histopathological analysis of the uterus and placenta of HEV-infected mice, $\times 20$. 


\section{Discussion}

HEV infection is the leading cause of acute viral hepatitis [1,33], which causes significant morbidity and mortality during pregnancy [34,35]. Miscarriage and stillbirth were reported in pregnant women infected by genotype 1 and genotype $4 \mathrm{HEV}[10,36]$. Genotype $3 \mathrm{HEV}$ infection was thought to be less-pathogenic in the maternal-fetal interface [7]. Genotype $4 \mathrm{HEV}$ infection is more severe than genotype $3 \mathrm{HEV}$ infection [37]. Li et al., reported the adverse pregnancy outcomes, including preterm birth, premature rupture of membranes and abortion, caused by genotype $4 \mathrm{HEV}$ infection in China [10], which indicated that a genotype $4 \mathrm{HEV}$ infection during pregnancy could also lead to severe adverse outcomes. However, the mechanism of high morbidity and mortality during pregnancy remains unclear.

The extremely high mortality in HEV-infected pregnant women urgently prompted us to establish an animal model of HEV infection in pregnancy to further study the pathogenesis. Although human HEV-infected non-human primates or swine fail to simulate the adverse outcomes of HEV infection in pregnancy $[38,39]$, pregnant rabbits were successfully infected with $\mathrm{HEV}$, which caused a $75 \%$ mortality rate and 33.33\% miscarriage rate [16]. Murine models, such as the BALB/c nude mouse [20], Mongolian gerbils [40] and BALB/c mouse [21] have been reported to be susceptive to genotype $4 \mathrm{HEV}$ infection, which is isolated from China. It has been reported that genotype 1 and $3 \mathrm{HEV}$ can infect humanized mice with chimeric human livers, but fail to infect C57BL/6 mice [41-43]. Thus, to further identify whether genotype 4 swine HEV will lead to high mortality and adverse outcomes in BALB/c mice, the most common animal model of HEV-infected pregnant mice was performed. It is encouraging that a high miscarriage rate $(87.5 \%)$ was observed in pregnant mice when infected with HEV in middle pregnancy. In the early pregnancy group, four mice were non-pregnant with unchanged estrogen and progesterone levels at 7 days post-copulation. It is possible that the miscarriage happened earlier than 7 days after pregnancy. Although higher viral titers were observed in the miscarriage mice compared with non-pregnant or normal delivery mice at $7 \mathrm{dpi}$, the different time points of post-copulation in the early and middle pregnancy groups may affect this result.

Moreover, a higher IL-12/IL-6 ratio (Th1-biased state) was found in HEV-infected mice with miscarriages than in uninfected MOCK or HEV-infected mice with normal deliveries. These HEV-infected mice with normal deliveries showed Th2-biased states, which are important to maintain pregnancy. The altered immune state caused by HEV infection during pregnancy from Th2-biased to Th1-biased has been observed in HEV-infected pregnant women with fulminant hepatic failure [27], which may be a miscarriage marker and should be carefully observed. However, no maternal death occurred in the HEV-infected mice, possibly because of the mice's short pregnancy cycle (21 days), the short-time inoculation of HEV (only $17 \mathrm{dpi}, 11 \mathrm{dpi}$, and $5 \mathrm{dpi}$ ) or the moderate clinical symptom caused by genotype $4 \mathrm{HEV}$. The pregnant BALB/c mice model is useful to study HEV infection during pregnancy because BALB/c mice are readily available, low-cost and easy to handle.

Vertical transmission of HEV infection has been noted since 1995 [44]; this type of transmission threatens fetal and neonatal health, and more importantly, results in maternal death. Miscarriage, stillbirth, or neonatal death were observed in $56 \%$ of infants whose mothers were infected with HEV [45]. However, the vertical transmission of HEV was controversial, because of the transmission rate from mother to infant varied from 100\% [46] to 17\% [47]. In addition, only a few studies identified that HEV replicates in placental tissues from HEV-infected women or in the maternal-fetal interface [7,48]. In the present study, HEV RNA and a large portion of HEV antigens were detected in the uterus and placenta of all HEV-infected mice, indicating that HEV replicates in the uterus and the placenta, which may contribute to miscarriage. Furthermore, we found that HEV can cross the blood placental barrier to infect the fetus. In addition, all the fetuses were infected by their HEV-infected mother, and the liver of an HEV-infected fetus was positive for HEV RNA and antigens. The transmission of HEV through the fecal-oral route from mother to their newborn fetus can be ignored because all baby mice gave birth by cesarean section. Although the adverse pregnancy outcomes of genotype $4 \mathrm{HEV}$ infection in pregnant women have usually been ignored, preterm births, premature rupture of membranes, and abortions 
were recently reported in clinical [10-12]. In the present study, a high miscarriage rate was found in pregnant mice infected by HEV in the middle stage of pregnancy, with severe inflammation responses in the uterus. Thus, more attention must be paid to pregnant women with jaundice, or an elevated activity/level of liver enzymes. There are no specific anti-HEV drugs in clinical, but RBV as an off-label drug is usually used for chronic hepatitis E treatment. In the present study, almost no antiviral effect was obtained after RBV treatment, because the KM01 strain contains a G1634R mutation in ORF1, which is reportedly associated with the treatment failure of RBV therapy in acute and chronic hepatitis E patients [49]. More importantly, the teratogenicity limits its use during pregnancy.

In summary, HEV infection in pregnant mice was successfully established with a high rate of miscarriage. This animal model can be used to model HEV infection in pregnant women to study the adverse outcomes caused by HEV and to explore host response and pathogenesis. This model is also important for future anti-HEV drug development.

Author Contributions: Conceptualization, F.H. and C.Y.; Methodology, C.Y.; Software, X.H.; Validation, Y.L., F.L. and Q.H.; Formal Analysis, C.Y.; Investigation, W.Y.; Resources, C.Y.; Data Curation, X.H.; Writing - Original Draft Preparation, C.Y.; Writing - Review \& Editing, X.H.; Visualization, Q.H.; Supervision, F.H.; Project Administration, F.H.; Funding Acquisition, F.H and W.Y.

Funding: This study was supported by the National Natural Science Foundation of China to Fen Huang (grant number 31360619 and 81660338), Fundamental Research Funds for the Central Universities (grant number 2016ZX310179-3) and the PUMC Youth Fund (grant number 2017310038) to Wenhai Yu, Natural Science Foundation of Yunnan province (grant number 2017FA036 to Fen Huang and 2018FB132 to Wenhai Yu).

Acknowledgments: We thank Xinyong Qi for the professorial palpation of the embryos and analysis of the histopathologic examination.

Conflicts of Interest: The authors declare no conflict of interest. The funders had no role in the study design, data collection and interpretation, or the decision to submit the work for publication.

\section{References}

1. Rein, D.B.; Stevens, G.A.; Theaker, J.; Wittenborn, J.S.; Wiersma, S.T. The global burden of hepatitis E virus genotypes 1 and 2 in 2005. Hepatology 2012, 55, 988-997. [CrossRef] [PubMed]

2. Aggarwal, R.; Jameel, S. Hepatitis E. Hepatology 2011, 54, 2218-2226. [CrossRef]

3. Emerson, S.U.; Purcell, R.H. Hepatitis E virus. Rev. Med. Virol. 2003, 13, 145-154. [CrossRef] [PubMed]

4. Kumar, A.; Beniwal, M.; Kar, P.; Sharma, J.B.; Murthy, N.S. Hepatitis E in pregnancy. Int. J. Gynaecol. Obs. 2004, 85, 240-244. [CrossRef]

5. Sultana, R.; Humayun, S. Fetomaternal outcome in acute hepatitis e. J. Coll Physicians Surg. Pak. 2014, 24, $127-130$.

6. Rayis, D.A.; Jumaa, A.M.; Gasim, G.I.; Karsany, M.S.; Adam, I. An outbreak of hepatitis E and high maternal mortality at Port Sudan, Eastern Sudan. Pathog Glob. Health 2013, 107, 66-68. [CrossRef] [PubMed]

7. Gouilly, J.; Chen, Q.; Siewiera, J.; Cartron, G.; Levy, C.; Dubois, M.; Al-Daccak, R.; Izopet, J.; Jabrane-Ferrat, N.; El Costa, H. Genotype specific pathogenicity of hepatitis $\mathrm{E}$ virus at the human maternal-fetal interface. Nat. Commun. 2018, 9, 4748. [CrossRef]

8. Perez-Gracia, M.T.; Suay-Garcia, B.; Mateos-Lindemann, M.L. Hepatitis E and pregnancy: Current state. Rev. Med. Virol. 2017. [CrossRef] [PubMed]

9. Navaneethan, U.; Al Mohajer, M.; Shata, M.T. Hepatitis E and pregnancy: Understanding the pathogenesis. Liver Int. Off. J. Int. Assoc. Study Liver 2008, 28, 1190-1199. [CrossRef]

10. Li, M.; Bu, Q.; Gong, W.; Li, H.; Wang, L.; Li, S.; Sridhar, S.; Cy Woo, P.; Wang, L. Hepatitis E virus infection and its associated adverse feto-maternal outcomes among pregnant women in Qinhuangdao, China. J. Matern. -Fetal Neonatal Med. Off. J. Eur. Assoc. Perinat. Med. Fed. Asia Ocean. Perinat. Soc. Int. Soc. Perinat. Obs. 2019. [CrossRef]

11. Zhong, Y.; $\mathrm{Xu}, \mathrm{H}$. Perinatal nursing care of the pregnant women with Viral hepatitis E. Mod. Dig. Interv. 2016, 21, 57-60. (In Chinese) [CrossRef]

12. Zhang, J. Nursing care of 20 cases pregnant women infected with Hepatitis E virus. Yiyao Qianyan 2015, 14, 238-239. (In Chinese) [CrossRef] 
13. Jilani, N.; Das, B.C.; Husain, S.A.; Baweja, U.K.; Chattopadhya, D.; Gupta, R.K.; Sardana, S.; Kar, P. Hepatitis E virus infection and fulminant hepatic failure during pregnancy. J. Gastroenterol. Hepatol. 2007, 22, 676-682. [CrossRef]

14. Bi, Y.; Yang, C.; Yu, W.; Zhao, X.; Zhao, C.; He, Z.; Jing, S.; Wang, H.; Huang, F. Pregnancy serum facilitates hepatitis E virus replication in vitro. J. Gen. Virol. 2015, 96, 1055-1061. [CrossRef]

15. Knegendorf, L.; Drave, S.A.; Dao Thi, V.L.; Debing, Y.; Brown, R.J.P.; Vondran, F.W.R.; Resner, K.; Friesland, M.; Khera, T.; Engelmann, M.; et al. Hepatitis E virus replication and interferon responses in human placental cells. Hepatol. Commun. 2018, 2, 173-187. [CrossRef]

16. Xia, J.; Liu, L.; Wang, L.; Zhang, Y.; Zeng, H.; Liu, P.; Zou, Q.; Wang, L.; Zhuang, H. Experimental infection of pregnant rabbits with hepatitis E virus demonstrating high mortality and vertical transmission. J. Viral Hepat. 2015, 22, 850-857. [CrossRef]

17. Liu, P.; Bu, Q.N.; Wang, L.; Han, J.; Du, R.J.; Lei, Y.X.; Ouyang, Y.Q.; Li, J.; Zhu, Y.H.; Lu, F.M.; et al. Transmission of hepatitis E virus from rabbits to cynomolgus macaques. Emerg. Infect. Dis. 2013, 19, 559-565. [CrossRef] [PubMed]

18. Izopet, J.; Dubois, M.; Bertagnoli, S.; Lhomme, S.; Marchandeau, S.; Boucher, S.; Kamar, N.; Abravanel, F.; Guerin, J.L. Hepatitis E virus strains in rabbits and evidence of a closely related strain in humans, France. Emerg. Infect. Dis. 2012, 18, 1274-1281. [CrossRef]

19. Zhao, C.; Ma, Z.; Harrison, T.J.; Feng, R.; Zhang, C.; Qiao, Z.; Fan, J.; Ma, H.; Li, M.; Song, A.; et al. A novel genotype of hepatitis E virus prevalent among farmed rabbits in China. J. Med. Virol. 2009, 81, 1371-1379. [CrossRef] [PubMed]

20. Huang, F.; Zhang, W.; Gong, G.; Yuan, C.; Yan, Y.; Yang, S.; Cui, L.; Zhu, J.; Yang, Z.; Hua, X. Experimental infection of Balb/c nude mice with Hepatitis E virus. Bmc Infect. Dis. 2009, 9, 93. [CrossRef]

21. Sun, Y.; Lu, Q.; Liu, B.; Sheng, Y.; Du, T.; Hiscox, J.A.; Zhou, E.M.; Zhao, Q. Cross-species infection of mice by rabbit hepatitis E virus. Vet. Microbiol. 2018, 225, 48-52. [CrossRef] [PubMed]

22. Huang, F.F.; Haqshenas, G.; Guenette, D.K.; Halbur, P.G.; Schommer, S.K.; Pierson, F.W.; Toth, T.E.; Meng, X.J. Detection by reverse transcription-PCR and genetic characterization of field isolates of swine hepatitis E virus from pigs in different geographic regions of the United States. J. Clin. Microbiol. 2002, 40, 1326-1332. [CrossRef]

23. Nanda, S.K.; Panda, S.K.; Durgapal, H.; Jameel, S. Detection of the negative strand of hepatitis E virus RNA in the livers of experimentally infected rhesus monkeys: Evidence for viral replication. J. Med. Virol. 1994, 42, 237-240. [CrossRef]

24. Baylis, S.A.; Blumel, J.; Mizusawa, S.; Matsubayashi, K.; Sakata, H.; Okada, Y.; Nubling, C.M.; Hanschmann, K.M. World Health Organization International Standard to harmonize assays for detection of hepatitis E virus RNA. Emerg. Infect. Dis. 2013, 19, 729-735. [CrossRef] [PubMed]

25. Huang, F.; Li, Y.; Yu, W.; Jing, S.; Wang, J.; Long, F.; He, Z.; Yang, C.; Bi, Y.; Cao, W.; et al. Excretion of infectious hepatitis E virus into milk in cows imposes high risks of zoonosis. Hepatology 2016, 64, 350-359. [CrossRef]

26. Huang, F.; Wang, J.; Yang, C.; Long, F.; Li, Y.; Li, L.; Jing, S.; Wang, H. Chinese pregnant women in their third trimester are more susceptible to HEV infection. Braz J. Infect. Dis 2015, 19, 672-674. [CrossRef] [PubMed]

27. Bose, P.D.; Das, B.C.; Kumar, A.; Gondal, R.; Kumar, D.; Kar, P. High viral load and deregulation of the progesterone receptor signaling pathway: Association with hepatitis E-related poor pregnancy outcome. J. Hepatol. 2011, 54, 1107-1113. [CrossRef] [PubMed]

28. Makhseed, M.; Raghupathy, R.; Azizieh, F.; Omu, A.; Al-Shamali, E.; Ashkanani, L. Th1 and Th2 cytokine profiles in recurrent aborters with successful pregnancy and with subsequent abortions. Hum. Reprod 2001, 16, 2219-2226. [CrossRef]

29. Salek Farrokhi, A.; Zarnani, A.H.; Moazzeni, S.M. Mesenchymal stem cells therapy protects fetuses from resorption and induces Th2 type cytokines profile in abortion prone mouse model. Transpl. Immunol. 2018, 47, 26-31. [CrossRef] [PubMed]

30. Krishnan, L.; Guilbert, L.J.; Wegmann, T.G.; Belosevic, M.; Mosmann, T.R. T helper 1 response against Leishmania major in pregnant C57BL/6 mice increases implantation failure and fetal resorptions. Correlation with increased IFN-gamma and TNF and reduced IL-10 production by placental cells. J. Immunol. 1996, 156, 653-662. 
31. Domino, M.; Domino, K.; Gajewski, Z. An application of higher order multivariate cumulants in modelling of myoelectrical activity of porcine uterus during early pregnancy. Biosystems 2018, 175, 30-38. [CrossRef]

32. Enders, A.C. Reasons for diversity of placental structure. Placenta 2009, 30, S15-S18. [CrossRef] [PubMed]

33. Mahtab, M.A.; Rahman, S.; Khan, M.; Karim, M.F. Hepatitis E virus is a leading cause of acute-on-chronic liver disease: Experience from a tertiary centre in Bangladesh. Hepatobiliary Pancreat. Dis. Int. 2009, 8, 50-52. [PubMed]

34. Labrique, A.B.; Sikder, S.S.; Krain, L.J.; West, K.P., Jr.; Christian, P.; Rashid, M.; Nelson, K.E. Hepatitis E, a vaccine-preventable cause of maternal deaths. Emerg. Infect. Dis. 2012, 18, 1401-1404. [CrossRef]

35. Lhomme, S.; Marion, O.; Abravanel, F.; Chapuy-Regaud, S.; Kamar, N.; Izopet, J. Hepatitis E Pathogenesis. Viruses 2016, 8, 212. [CrossRef]

36. Kamar, N.; Dalton, H.R.; Abravanel, F.; Izopet, J. Hepatitis E virus infection. Clin. Microbiol. Rev. 2014, 27, 116-138. [CrossRef] [PubMed]

37. Jeblaoui, A.; Haim-Boukobza, S.; Marchadier, E.; Mokhtari, C.; Roque-Afonso, A.M. Genotype 4 hepatitis e virus in france: An autochthonous infection with a more severe presentation. Clin. Infect. Dis.: Off. Publ. Infect. Dis. Soc. Am. 2013, 57, e122-e126. [CrossRef]

38. Arankalle, V.A.; Chadha, M.S.; Banerjee, K.; Srinivasan, M.A.; Chobe, L.p. p. Hepatitis E virus infection in pregnant rhesus monkeys. Indian J. Med. Res. 1993, 97, 4-8.

39. Kasorndorkbua, C.; Thacker, B.J.; Halbur, P.G.; Guenette, D.K.; Buitenwerf, R.M.; Royer, R.L.; Meng, X.J. Experimental infection of pregnant gilts with swine hepatitis E virus. Can. J. Vet. Res. 2003, 67, 303-306.

40. Soomro, M.H.; Shi, R.; She, R.; Yang, Y.; Wang, T.; Wu, Q.; Li, H.; Hao, W. Molecular and structural changes related to hepatitis E virus antigen and its expression in testis inducing apoptosis in Mongolian gerbil model. J. Viral. Hepat. 2017, 24, 696-707. [CrossRef]

41. Li, T.C.; Suzaki, Y.; Ami, Y.; Tsunemitsu, H.; Miyamura, T.; Takeda, N. Mice are not susceptible to hepatitis E virus infection. J. Vet. Med. Sci 2008, 70, 1359-1362. [CrossRef] [PubMed]

42. Li, T.C.; Wakita, T. Small Animal Models of Hepatitis E Virus Infection. Cold Spring Harb. Perspect. Med. 2018. [CrossRef] [PubMed]

43. Schlosser, J.; Dähnert, L.; Dremsek, P.; Tauscher, K.; Fast, C.; Ziegler, U.; Gröner, A.; Ulrich, R.G.; Groschup, M.H.; Eiden, M. Different Outcomes of Experimental Hepatitis E Virus Infection in Diverse Mouse Strains, Wistar Rats, and Rabbits. Viruses 2019, 11, 1. [CrossRef]

44. Khuroo, M.S.; Kamili, S.; Jameel, S. Vertical transmission of hepatitis E virus. Lancet 1995, 345, $1025-1026$. [CrossRef]

45. Naidu, S.S.; Viswanathan, R. Infectious hepatitis in pregnancy during Delhi epidemic. Indian J. Med. Res. 1957, 45, 71-76.

46. Kumar, R.M.; Uduman, S.; Rana, S.; Kochiyil, J.K.; Usmani, A.; Thomas, L. Sero-prevalence and mother-to-infant transmission of hepatitis E virus among pregnant women in the United Arab Emirates. Eur. J. Obstet. Gynecol. Reprod. Biol. 2001, 100, 9-15. [CrossRef]

47. El Sayed Zaki, M.; El Aal, A.A.; Badawy, A.; El-Deeb, D.R.; El-Kheir, N.Y. Clinicolaboratory study of mother-to-neonate transmission of hepatitis E virus in Egypt. Am. J. Clin. Pathol. 2013, 140, 721-726. [CrossRef]

48. Bose, P.D.; Das, B.C.; Hazam, R.K.; Kumar, A.; Medhi, S.; Kar, P. Evidence of extrahepatic replication of hepatitis E virus in human placenta. J. Gen. Virol. 2014, 95, 1266-1271. [CrossRef]

49. Debing, Y.; Gisa, A.; Dallmeier, K.; Pischke, S.; Bremer, B.; Manns, M.; Wedemeyer, H.; Suneetha, P.V.; Neyts, J. A mutation in the hepatitis E virus RNA polymerase promotes its replication and associates with ribavirin treatment failure in organ transplant recipients. Gastroenterology 2014, 147, 1008-1011. [CrossRef]

(C) 2019 by the authors. Licensee MDPI, Basel, Switzerland. This article is an open access article distributed under the terms and conditions of the Creative Commons Attribution (CC BY) license (http://creativecommons.org/licenses/by/4.0/). 